\title{
Wind and ship wave-induced resuspension in the littoral zone of a large lake
}

\author{
Hilmar Hofmann, ${ }^{1}$ Andreas Lorke, ${ }^{2}$ and Frank Peeters ${ }^{1}$ \\ Received 21 September 2010; revised 12 May 2011; accepted 25 May 2011; published 3 September 2011.
}

[1] Sediment resuspension in lake littoral zones (nearshore region) is strongly related to the properties of the surface wavefield. The occurrence and characteristics of surface waves, near-bottom current velocities, and related suspended sediment concentrations and properties were measured simultaneously in Lake Constance over 1 year. Wind and ship waves are distinguished on the basis of their typical properties, enabling a detailed investigation of their respective importance for sediment resuspension. In the littoral zone of Lake Constance, resuspension occurred during $25 \%$ of the entire observation period. Of those observations, 54\% were caused by ship waves, which therefore were as important for resuspension as wind waves. Resuspension induced by wind waves occurs rather sporadically throughout the year, whereas ship wave-induced resuspension occurs regularly during the daytime in summer and is hence associated with pronounced diurnal and seasonal patterns in the suspended sediment concentration.

Citation: Hofmann, H., A. Lorke, and F. Peeters (2011), Wind and ship wave-induced resuspension in the littoral zone of a large lake, Water Resour. Res., 47, W09505, doi:10.1029/2010WR010012.

\section{Introduction}

[2] Sediment resuspension on continental shelves [e.g., Dyer, 1986; Nielson, 1994], in estuaries [Defendi et al., 2010; Hamblin, 1989], rivers [e.g., El Ganaoui et al., 2004; Garrad and Hey, 1987], and lakes [e.g., Håkanson, 2005; Hawley and Lesht, 1992; Luettich et al., 1990] and their corresponding driving forces (e.g., tidal currents, surface waves, and wave-current interactions) have been intensively studied.

[3] Resuspension and reallocation of particles primarily changes the sediment structure (consolidated/unconsolidated) but also creates varying abiotic and biotic habitat conditions for the growth of phytoplankton, biofilms, and macrophytes by, for example, nutrient and methane release [e.g., Hofmann et al., 2010; Søndergaard et al., 1992], oxygenation of the sediment surface layer [e.g., Precht et al., 2004], or a change in the light climate [Erm and Soomere, 2006; Pierson et al., 2003].

[4] In the littoral zone (nearshore region) of small and large lakes, surface waves are the most important cause of resuspension because of the absence of tides, large river inflow, and synoptic-scale motions. The characterization of surface waves, however, is mainly based on studies in marine and shelf regions [e.g., Komen et al., 1996; Le Blond and Mysak, 1978], where waves are mostly generated by strong and steady winds over long fetch lengths. In most lakes winds are infrequent and unsteady, wind speeds are low, and the effective fetch is limited to a few kilometers. Wind waves in lakes are thus characterized by small amplitudes, high fre-

\footnotetext{
${ }^{1}$ Environmental Physics, Limnological Institute, University of Konstanz, Konstanz, Germany.

${ }^{2}$ Institute for Environmental Sciences, University of Koblenz-Landau, Landau, Germany.

Copyright 2011 by the American Geophysical Union. 0043-1397/11/2010WR010012
}

quencies, and short wavelengths [e.g., Allan and Kirk, 2000; Hofmann et al., 2008b] and usually differ considerably from waves in the ocean. Because of the short wavelengths of wind waves in lakes, their potential for resuspension is smaller than that of wind waves in the ocean.

[5] In addition to wind waves, commercial and tourist ship traffic also create surface waves. The properties and importance of ship waves have been investigated in rivers and channels [e.g., Bhowmik et al., 1991; Garrad and Hey, 1987; Sorensen, 1973], in ocean shelf regions and harbors [e.g., Parnell and Kofoed-Hansen, 2001; Soomere and Engelbrecht, 2005; Stumbo, 1999], and in lakes [e.g., Bhowmik, 1975; Hofmann et al., 2008b; Maynord, 2005]. Wind and ship waves frequently have considerably different wave properties (e.g., wave periods and lengths), which allow to distinguish between the two types of waves in measurements [Hofmann et al., 2008b]. The different properties of wind and ship waves are associated with different implications for resuspension and ecological consequences in the littoral zone [e.g., Eriksson et al., 2004; Erm and Soomere, 2006; Soomere et al., 2009].

[6] Wind and ship wave-induced sediment resuspension are mostly considered separately: wind wave-induced resuspension was considered by, e.g., Hawley and Lesht [1992], Kristensen et al. [1992], and Vittori [2003], and ship waveinduced resuspension was considered by, e.g., Lindholm et al. [2001], Parchure et al. [2001], and Schoellhamer [1996]. Only a few recent studies have focused on the relative importance of wind and ship waves for sediment resuspension or erosion in ocean shelf regions [Houser, 2010; Kelpsaite et al., 2009; Soomere, 2005]. Similar investigations in lakes, however, are lacking.

[7] Here, we investigate the dynamics, temporal patterns, and relative importance of wind and ship waves for the resuspension of sediments by analyzing a yearlong record of continuously measured surface wave properties, waveinduced near-bottom current velocities, and related sus- 


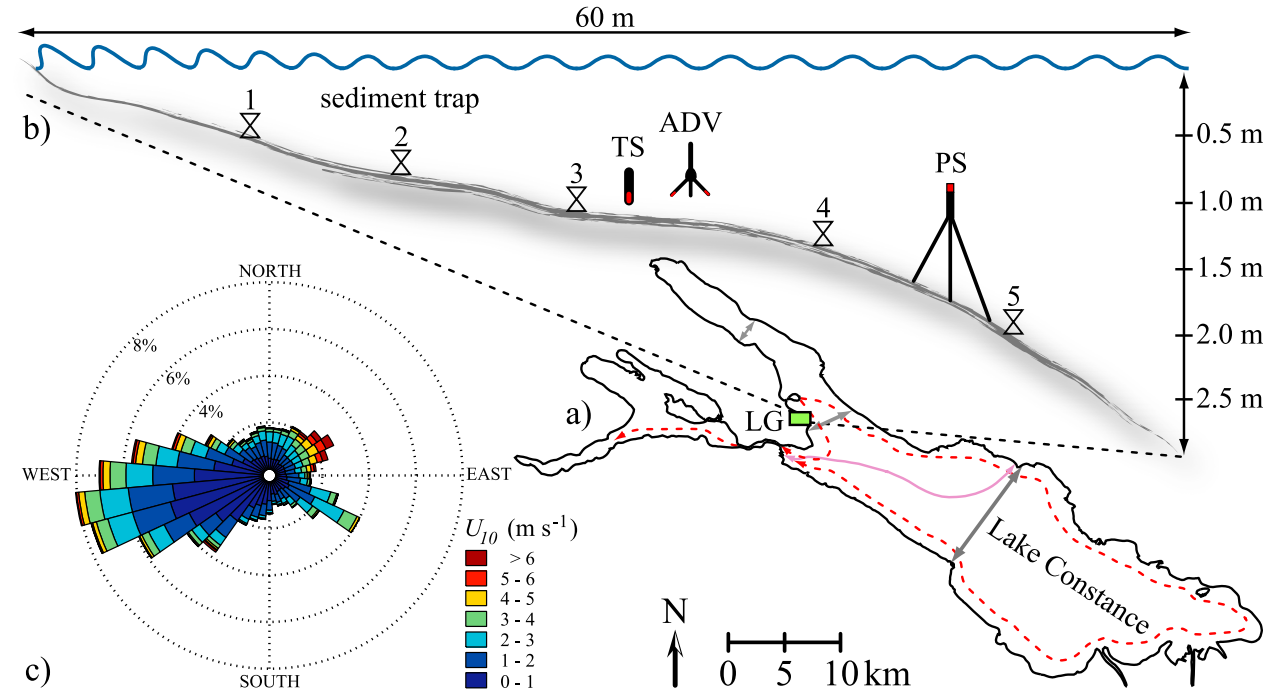

Figure 1. Study site, experimental setup, and wind exposure. (a) Map of Lake Constance with major boat routes: ferries (solid gray line), passenger ships (dashed red line), and catamaran ferry (solid magenta

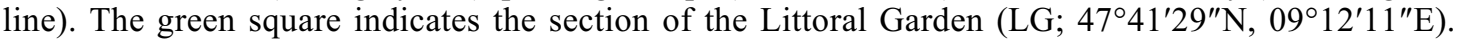
(b) Cross section of the study site LG with all instruments used: PS, pressure sensor; ADV, acoustic Doppler velocity meter; TS, turbidity sensor; 1-5, sediment traps. (c) Wind exposure of the study site LG between August 2005 and July 2006: relative frequency of direction and related wind speed $\left(U_{10}\right)$. Values are averaged per $10^{\circ}$ direction.

pended sediment concentrations and properties in the littoral zone of a large lake.

\section{Materials and Methods}

\subsection{Study Site}

[8] Lake Constance, the second-largest (by surface area, $536 \mathrm{~km}^{2}$ ) prealpine lake in Europe, is located in the southwest of Germany. The littoral zone, where most of the energy of the surface waves is dissipated, covers about $10 \%$ of the total surface area [Braun and Schärpf, 1990]. Measurements were made in the western part of Upper Lake Constance at a site called the Littoral Garden (LG; $47^{\circ} 41^{\prime} 29^{\prime \prime} \mathrm{N}, 09^{\circ} 12^{\prime} 11^{\prime \prime} \mathrm{E}$ ) (Figure 1a). At the LG, the littoral zone has a shelf-like structure, sloping gently over a length of about $60 \mathrm{~m}$ before it drops rapidly. The shallow part (0-1 m water depth) of the nearshore is characterized by a mixture of gravel, pebbles and cobbles, sand and silt, and the deeper part (1-2 $\mathrm{m}$ water depth) by sand, silt and clay.

\subsubsection{Wind Exposure}

[9] A meteorological station $1 \mathrm{~km}$ to the west of the study site provided $20 \mathrm{~min}$ averages of wind speed $\left(U_{10}\right)$ and wind direction ( $U_{10}$ Dir) $10 \mathrm{~m}$ above lake level during 2005 and 2006. Westerly winds are most frequent during the year, but the associated wind speeds were moderate at the study site (Figure 1c). The second most frequent winds come from southeast (mainly during summer) and northeast (mainly during winter) [Hofmann et al., 2008b]. The study site is exposed to northeasterly winds that are associated with the highest wind speeds. The effective fetch length for northeasterly winds ranges between 3 and $4 \mathrm{~km}$.

\subsubsection{Wavefield Characteristics}

[10] The study site is exposed to a highly variable surface wavefield that consists of both wind and ship waves (see Figures 5c, 5d, 5j, and 5k) [Hofmann et al., 2008b].
[11] Relatively high wind waves occur during northern and northeastern winds. Strong and long-lasting wind events create maximum wave heights between 0.7 and $0.8 \mathrm{~m}$. The wave periods are between 1 and $2.3 \mathrm{~s}$ and the corresponding deepwater wavelengths between 2 and $8 \mathrm{~m}$.

[12] Ship waves stem from a nearby ferry route that runs regularly throughout the year, from passenger ships traveling parallel to the shore $(0.5-1 \mathrm{~km}$ distance) between midMarch and mid-October, and from a catamaran ferry that operates about $5 \mathrm{~km}$ away from the study site. Ship waves occur not only around the study site LG but are a ubiquitous feature on Lake Constance (Figure 1a). Ferries, passenger ships, and the catamaran have wave heights of 0.04-0.15, $0.1-0.4$, and $<0.05 \mathrm{~m}$, wave periods of $3.7,2.9$, and $6.3 \mathrm{~s}$, and wavelengths of 19,13 , and up to $50 \mathrm{~m}$, respectively.

[13] Wind waves occur rather sporadically (during the study period only eleven strong wind events were observed during which wave heights exceeded $0.4 \mathrm{~m}$ ), whereas ship waves occur frequently and typically are the predominant waves during daytime and in summer. Ship waves thus cause a diurnal and seasonal pattern of the wavefield with high and frequently occurring waves during daytime, especially in summer, and nearly no waves at night.

\subsection{Wave and Current Velocity Measurements}

[14] The surface wavefield and wave-generated nearbottom current velocities were studied using a pressure sensor (PS) and a NORTEK Vector acoustic Doppler velocity meter (ADV). Both instruments were deployed between August 2005 and July 2006 along a cross-shore transect at water depths of about $2 \mathrm{~m}$ (PS) and 1-3 m (ADV), respectively (Figure 1b). The position of both instruments was adjusted monthly to compensate for seasonal water level fluctuations of about 2-3 m [e.g., Hofmann et al., 2008c].

[15] The custom-made PS has a full-scale range of $7 \mathrm{~m}$, an accuracy of $0.1 \mathrm{mbar}$, and a maximum stand-alone deploy- 
ment time of $60 \mathrm{~d}$. The sensor was always positioned $1 \mathrm{~m}$ above the bottom and about $1 \mathrm{~m}$ below the surface. Pressure measurements were made at a sampling frequency of $16 \mathrm{~Hz}$ during the entire deployment period. Sensor malfunction caused a data gap in February 2006. The measured time series of subsurface pressure was converted to a time series of surface elevation following the procedure described by Hofmann et al. [2008b]. Maximum and significant wave heights $\left(H_{\max }, H_{s}\right)$ and significant period $\left(T_{s}\right)$ were estimated for segments of 1,024 samples $(\sim 1.1 \mathrm{~min})$ by using the zeroupcrossing method [Hofmann et al., 2008b; IAHR Working Group on Wave Generation and Analysis, 1989]. On 16 and 17 August 2005, the same procedure as for the PS was used for the pressure time series of the ADV to estimate the wave parameters $H_{\max }$ and $T_{s}$.

[16] The ADV and the data acquisition system were attached to a bottom-resting tripod. The sensor head faced downward with its sampling volume located $0.05 \mathrm{~m}$ above the bottom. The near-bottom current velocities were measured within a range of $\pm 0.3 \mathrm{~m} \mathrm{~s}^{-1}$ with an accuracy of $10^{-3} \mathrm{~m} \mathrm{~s}^{-1}$ and a sampling frequency of $8 \mathrm{~Hz}$. The near-bottom current speed was calculated from the two horizontal components of the measured current velocities and later used for all subsequent and statistical analyses.

\subsection{Suspended Sediment Measurements}

[17] Measurements of suspended particles were carried out using an optical backscatter sensor (turbidity sensor (TS), Driesen \& Kern) and by evaluating the acoustical backscatter strength recorded by the ADV. The TS was attached to the tripod at a height of $0.2 \mathrm{~m}$ above the bottom (Figure 1b) between August and October 2005. Turbidity was measured with an accuracy of 0.01 FTU and at a sampling frequency of $0.1 \mathrm{~Hz}$.

[18] The suspended sediment concentrations (SSC) can be measured by optical as well as by acoustical sensors in terms of backscatter strength. The calibration, application, and limitations of these methods have been extensively discussed [e.g., Fugate and Friedrichs, 2002; Lynch et al., 1994]. Here the optical and acoustical backscatter strengths were calibrated against SSC measured in water samples $(5 \mathrm{~L})$ collected near the TS and the ADV sampling volumes. Samples were collected on August 03 and 16, 2005, when the wavefield was dominated by ship waves, and on 18 September 2005 during a strong onshore wind. The samples were vacuumpumped using $0.45 \mu \mathrm{m}$ GF 6 Schleicher \& Schuell glass fiber filters and then dried at $105^{\circ} \mathrm{C}$ for $24 \mathrm{~h}$. Mass difference between the packed and the empty filter was used to calculate the suspended sediment concentration $\mathrm{SSC}\left(\mathrm{mg} \mathrm{L}^{-1}\right)$. The set of samples covers varying forcing conditions for resuspension (wind and ship waves), and thus compensates for possible uncertainties in the optical and acoustical backscatter measurements arising from changing size distributions and flocculation of the particles [e.g., Fugate and Friedrichs, 2002; Thevenot and Kraus, 1993; Voulgaris and Meyers, 2004]. The calibration equations were established by fitting a linear model $\left(\mathrm{SSC}_{\mathrm{TS}}=1.58 \times \mathrm{OBS}-26.8, R^{2}=\right.$ $0.98, n=31)$ to the optical backscatter strength (OBS) and an exponential model $\left(\mathrm{SSC}_{\mathrm{ADV}}=0.0048 e^{0.0674 \mathrm{ABS}}, R^{2}=0.88\right.$, $n=31$ ) to the acoustical backscatter strength (ABS) and the SSC. The measured optical and acoustical backscatter strengths were afterward converted into $\mathrm{SSC}\left(\mathrm{SSC}_{\mathrm{TS}}\right.$ and $\left.\mathrm{SSC}_{\mathrm{ADV}}\right)$.

\subsection{Characterization of the Sediment}

\subsubsection{Sediment Traps}

[19] Sedimentation rates of organic and inorganic material were measured by five cylindrical sediment traps evenly distributed along a transect perpendicular to shore in the shallow littoral (water depths: $0.5-2.2 \mathrm{~m}$ ) at the study site LG between August 2005 and July 2006 (Figure 1b). The deployment durations varied between five days and six weeks. The sediment traps had a diameter of $0.05 \mathrm{~m}$ and the opening of the cylinder was $0.25 \mathrm{~m}$ above the bottom. Sediment samples were dried at $105^{\circ} \mathrm{C}$ for $24 \mathrm{~h}$ and the dry weight and the resulting sedimentation rate per day and square meter were calculated. The amount of organic material (fraction) in the sediment samples was estimated as the ignition loss after exposure in a muffle furnace (HERAEUS) at $550^{\circ} \mathrm{C}$ over $8 \mathrm{~h}$. The mass of sediment remaining after exposure in the furnace is considered as inorganic material (fraction) [Ball, 1964; Guy, 1969].

\subsubsection{Grain Size Distribution}

[20] The grain size distribution in water samples, sediment traps, and surface sediments was measured by the Saturn DigiSizer 5200 high-resolution laser particle size analyzer, providing size distributions in the range between 0.001 and $1 \mathrm{~mm}$ with an accuracy of $3 \%$. Note that only inorganic particles, which aggregate much less readily than organic particles, can be measured accurately with this technique. All samples were therefore ignited in a muffle furnace (see above) so that only the inorganic fraction was analyzed.

[21] Figure 2 shows typical particle size distributions measured in water samples and in samples from the sediment traps. The median grain size $\left(d_{50}\right)$ of particles in the sediment traps and suspended in water samples at the study site LG was estimated from the measured grain size distributions following Dyer [1986] to be about $0.06 \mathrm{~mm}$.

\subsubsection{Sediment Density}

[22] The sediment density $\rho_{s}\left(\mathrm{~kg} \mathrm{~m}^{-3}\right)$ was experimentally determined with a pycnometer as described by IFMGEOMAR (Methods: Determination of density in solid samples, http://www.ifm-geomar.de/index.php?id=1916\&L=1). For this purpose, samples were taken from the sediment top layer $(1-2 \mathrm{~cm})$ and from the sediments collected in traps.

[23] The particles in the top layer of the sediments, collected near the sediment traps, TS, and ADV had a density between 2500 and $2600 \mathrm{~kg} \mathrm{~m}^{-3}$. These particles are potentially available for resuspension. The particles collected in the sediment traps, however, had a density between 2000 and $2200 \mathrm{~kg} \mathrm{~m}^{-3}$.

\subsection{Statistics on Wave-Generated Current Velocities and Suspended Particles}

[24] The wave-generated maximum near-bottom current velocity $u_{\max , \mathrm{ADV}}$ and the mean suspended particle concentration determined from the ADV backscatter strength $\mathrm{SSC}_{\mathrm{ADV}}$ were evaluated for burst intervals of 1.1 and $30 \mathrm{~min}$. Within each burst, $u_{\max , \mathrm{ADV}}$ is defined as the mean of the top one percentile of current velocities and $\mathrm{SSC}_{\mathrm{ADV}}$ is defined as the mean of all SSC determined from the ADV backscatter strength during the respective burst interval. The time series of $u_{\text {max }, \mathrm{ADV}}$ and $\mathrm{SSC}_{\mathrm{ADV}}$ for $1.1 \mathrm{~min}$ burst intervals were employed in the comparison with the time series of $u_{\text {max,PS }}$ (see below) and $\mathrm{SSC}_{\mathrm{TS}}$ (calculated from the optical backscatter sensor), both also determined at $1.1 \mathrm{~min}$ burst 


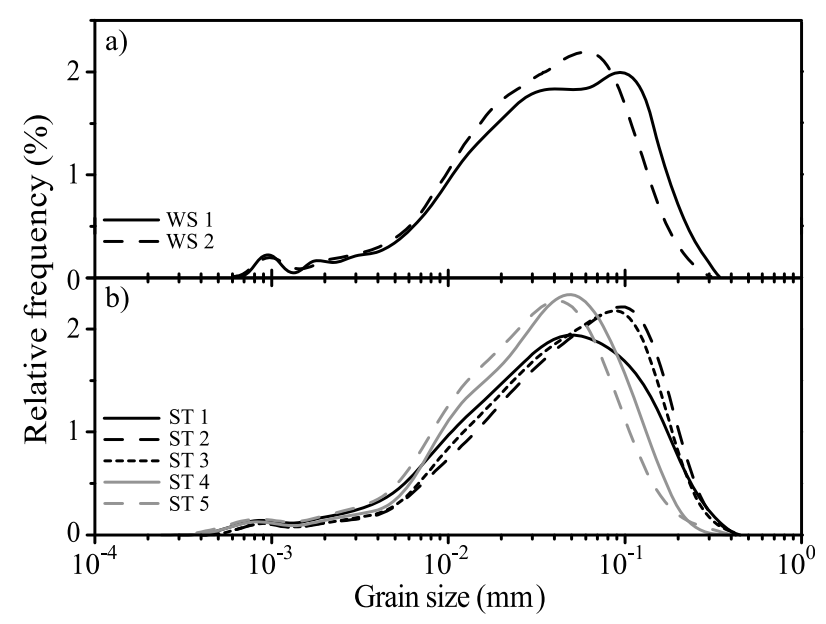

Figure 2. Characteristic grain size distributions of suspended particles in the shallow littoral at the Littoral Garden (LG). (a) Water samples (WS) collected during the passage of a single ship wave group at $1 \mathrm{~m}$ water depth. The solid line (WS 1) gives the grain size distribution at the maximum of the wave-generated current velocity, and the dashed line (WS 2) gives the distribution at $30 \mathrm{~s}$ afterward. (b) Sediment traps (ST) deployed $0.25 \mathrm{~m}$ above bottom at $0.5 \mathrm{~m}$ (ST 1, solid black line), $0.7 \mathrm{~m}$ (ST 2, long-dashed black line), $0.9 \mathrm{~m}$ (ST 3, short-dashed black line), 1.2 (ST 4, solid gray line), and $1.9 \mathrm{~m}$ (ST 5, dashed gray line) water depth.

intervals that reflect the typical duration of a single ship wave group (Figure $4 \mathrm{a}$ ). The $u_{\text {max,ADV }}$ and $\mathrm{SSC}_{\mathrm{ADV}}$ evaluated for 30 min time intervals were employed in the estimation of the threshold near-bottom current velocity required for sediment resuspension at the study site. Changes in pressure and current velocity are instantaneously connected to the occurrence of surface waves, whereas the decline of SSC after a resuspension event is comparatively slow. Within 30 min particle settling typically leads to a substantial decline in SSC (Figures $5 \mathrm{f}$ and $5 \mathrm{~g}$ ). Hence, using $30 \mathrm{~min}$ time intervals supports that high SSC concentrations are adequately connected to a resuspension event.

[25] The relative importance of wind and ship waves for sediment resuspension in terms of the relative monthly frequency of resuspension $\left(\mathrm{RF}_{\text {res }}\right)$, proportion of time where the maximum near-bottom current velocity exceeds the calculated threshold for resuspension $\left(u_{\text {max,res }}=0.09 \mathrm{~m} \mathrm{~s}^{-1}\right.$, see section 3.2) was estimated from the distribution of their associated maximum near-bottom current velocity $u_{\max }$, PS calculated from the wave parameters [Brown et al., 2005]:

$$
u_{\max , \mathrm{PS}}=\frac{\pi H}{T \sinh \frac{2 \pi h}{\lambda}}\left(\mathrm{m} \mathrm{s}^{-1}\right)
$$

where $H$ denotes the wave height (m), $T$ the wave period (s), $h$ the water depth (m), and $\lambda$ the wavelength (m). $H_{\max }$ and $T_{s}$ are estimated from the PS, and $\lambda$ is calculated as a function of $T_{s}$ using the dispersion relation provided by Fenton and McKee [1990]. Here $u_{\max , \mathrm{Ps}}$ is considered at a water depth of $1 \mathrm{~m}$. We assumed that $H_{\max }$ and $T_{s}$ do not change significantly between 1 and $2 \mathrm{~m}$ water depth. The value of $u_{\text {max,PS }}$ is calculated for each wave burst interval considering burst intervals of $\sim 1.1 \mathrm{~min}$.
[26] All time intervals are classified as wind or ship wave dominated on the basis of the wave periods and wave heights during the respective time interval. Because ship waves in Lake Constance have wave periods above $2.5 \mathrm{~s}$ and do not exceed wave heights of $0.4 \mathrm{~m}$ [Hofmann et al., 2008b], all time intervals during which the significant wave period was above $2.5 \mathrm{~s}$ and the maximum wave height below $0.4 \mathrm{~m}$ were categorized as ship wave dominated, whereas all other time intervals are considered to be wind wave dominated. We further distinguished between daytime (09:00-21:00 LT) and nighttime (21:00-09:00 LT).

[27] The use of $u_{\text {max,Ps }}$ for the statistical analysis is affirmed by the comparison of the measured (ADV) and calculated (PS) maximum near-bottom current velocity $\left(u_{\max , \mathrm{ADV}}\right.$ and $\left.u_{\text {max,PS }}\right)$ at about $1 \mathrm{~m}$ water depth during August 2005 (Figure 3 ). The scatterplot reveals a good correlation between $u_{\text {max }, \mathrm{PS}}$ and $u_{\max , \mathrm{ADV}}\left(R^{2}=0.68\right)$, although the estimates for $u_{\text {max,PS }}$ are slightly higher than $u_{\text {max, } \mathrm{ADV}}$ at the upper limit of the ADV measurement range $\left( \pm 0.3 \mathrm{~m} \mathrm{~s}^{-1}\right)$. Possible reasons for the deviation from the 1:1 relation between the two time series include water level fluctuations during the period under consideration and the slight distortion of the wave form, especially from ship waves in shallow waters.

[28] The remobilization of particles under oscillatory flow due to surface waves can be determined from empirical equations. For noncohesive sediments with a median grain size $d_{50}$ between 0.063 and $2 \mathrm{~mm}$ (sand fraction), the appropriate threshold flow velocity $u_{\text {max,res }}$ is [U.S. Army Coastal Engineering Research Center, 2002; Hallermeier, 1980]

$$
u_{\text {max }, \text { res }}=\sqrt{8\left(\frac{\rho_{s}}{\rho_{w}}-1\right) g d_{50}}\left(\mathrm{~m} \mathrm{~s}^{-1}\right)
$$

where $d_{50}$ is the median grain size $(\mathrm{m}), g$ the gravitational acceleration $\left(\mathrm{m} \mathrm{s}^{-2}\right), \rho_{s}$ the sediment density $\left(\mathrm{kg} \mathrm{m}^{-3}\right)$, and

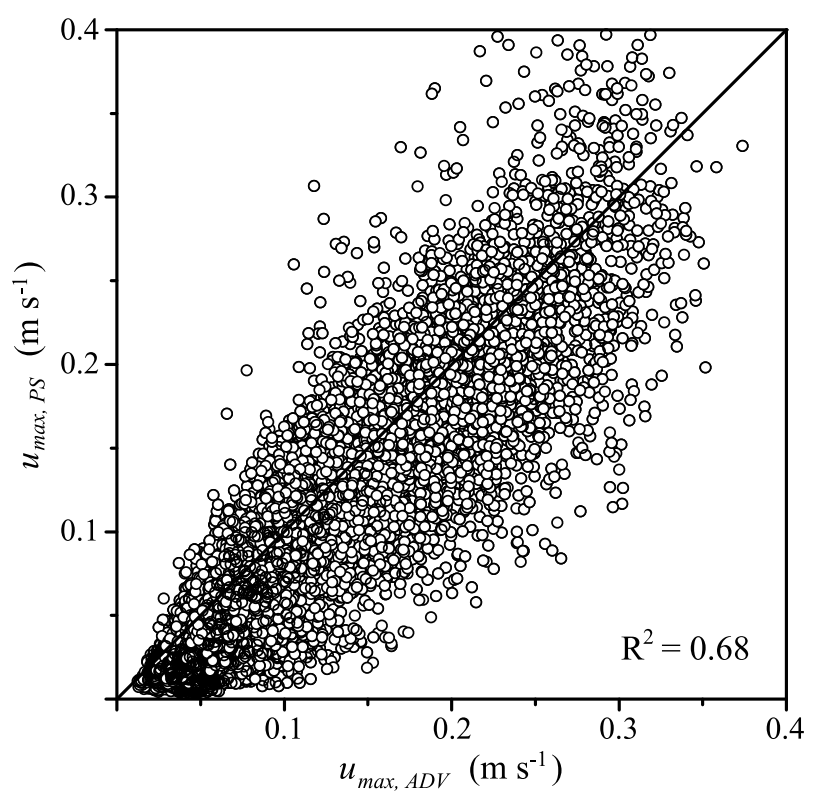

Figure 3. Comparison of the measured $\left(u_{\max , \mathrm{ADV}}\right)$ and calculated $\left(u_{\max , \mathrm{PS}}\right)$ maximum near-bottom current velocities at about $1 \mathrm{~m}$ water depth during August 2005. Each open circle represents a $1 \mathrm{~min}$ time period. The line indicates the $1: 1$ relation. 


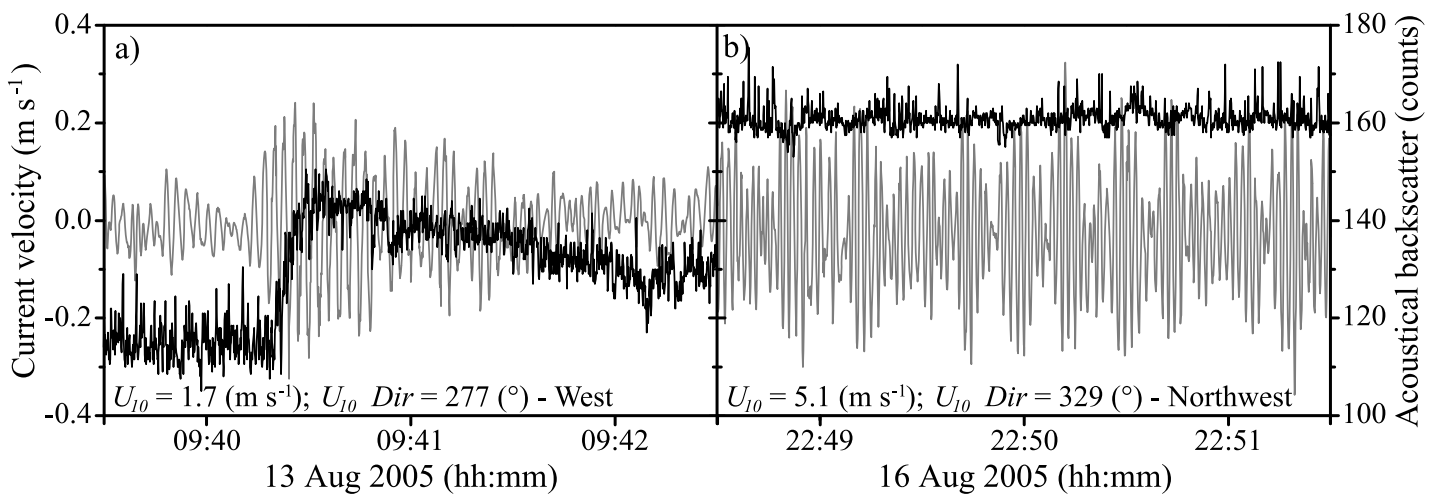

Figure 4. Magnitude of near-bottom current velocity (gray line) and the acoustical backscatter strength (black line) measured simultaneously by an ADV at $1 \mathrm{~m}$ water depth. (a) During the passage of a ship wave group on 13 August 2005. (b) During a strong onshore wind event on 16 August 2005.

$\rho_{w}$ the density of water $\left(\mathrm{kg} \mathrm{m}^{-3}\right)$. At the study site $\mathrm{LG}$, the suspended sediment has a density $\rho_{s}$ of $\sim 2,200 \mathrm{~kg} \mathrm{~m}^{-3}$ and a median grain size $d_{50}$ of $\sim 0.06 \mathrm{~mm}$. Following equation (2) the threshold flow velocity to initiate the remobilization of particles at the study site LG would be about $0.08 \mathrm{~m} \mathrm{~s}^{-1}$.

\section{Results}

\subsection{Patterns of Wave-Induced Resuspension}

[29] At the study site LG, wind as well as ship waves can cause near-bottom current velocities that are sufficient to induce resuspension and increase the load of suspended particles in the water column. Figure 4 exemplifies the dynamics and temporal patterns of the near-bottom current velocity and the acoustical backscatter strength measured by the ADV during the passage of a ship wave group on 13 August 2005 during low winds $\left(U_{10}=1.7 \mathrm{~m} \mathrm{~s}^{-1}\right.$ from west; Figure 4a) and during a strong onshore wind event on 16 August $2005\left(U_{10}=5.1 \mathrm{~m} \mathrm{~s}^{-1}\right.$ from northwest; Figure $\left.4 \mathrm{~b}\right)$. Whereas the oscillating currents associated with the wind and ship waves had comparable amplitudes of about $\pm 0.2-$ $0.3 \mathrm{~m} \mathrm{~s}^{-1}$, the acoustical backscatter strength showed a different pattern for wind and ship waves. During the passage of ship waves, the acoustical backscatter strength increased drastically within seconds as soon as the current velocity exceeded the determined threshold velocity of $0.09 \mathrm{~m} \mathrm{~s}^{-1}$ (see below). Afterward, the acoustical backscatter strength remained at a maximum value before it decreased slowly within minutes to its previous level (Figure 4a), mostly because of settling. During the wind event on 16 August 2005, the acoustical backscatter strength remained at a very high level because continuously high current velocities prevented particle settling. The continuously high backscatter strength suggests that an equilibrium between resuspension, settling, and transport of particles had been reached.

[30] The longer-term times series of the wind field, the wave parameters $\left(H_{\max }\right.$ and $\left.T_{s}\right)$, the maximum near-bottom current velocity measured by the $\mathrm{ADV}\left(u_{\max , \mathrm{ADV}}\right)$, and the $\mathrm{SSC}$ derived from the acoustical $\left(\mathrm{SSC}_{\mathrm{ADV}}\right)$ and the optical backscatter strengths $\left(\mathrm{SSC}_{\mathrm{TS}}\right)$ represent typical patterns of resuspension at the study site that are characteristic for periods dominated by ship waves (Figures $5 \mathrm{a}-5 \mathrm{~g}$ ) or wind waves (Figures $5 \mathrm{~h}-5 \mathrm{n}$ ). During both time periods, the $\mathrm{SSC}_{\mathrm{ADV}}$ and $\mathrm{SSC}_{\mathrm{TS}}$ agreed quite well, although short-term peak values of $\mathrm{SSC}_{\mathrm{TS}}$ were slightly lower than those of $\mathrm{SSC}_{\mathrm{ADV}}$ because of the lower temporal resolution and slightly higher position of the TS $(0.1 \mathrm{~Hz}, 0.2 \mathrm{~m})$ above the sediment compared to the ADV ( $8 \mathrm{~Hz}, 0.05 \mathrm{~m})$ (Figures $5 \mathrm{f}$, $5 \mathrm{~g}, 5 \mathrm{~m}$, and $5 \mathrm{n}$ ). During the summer months, when onshore wind events are rare, the SSC were characterized by a distinct diurnal cycle with low values $\left(0-5 \mathrm{mg} \mathrm{L}^{-1}\right)$ at night and high values $\left(50-150 \mathrm{mg} \mathrm{L}^{-1}\right)$ during the day (Figures $5 \mathrm{f}$ and $5 \mathrm{~g}$ ). The diurnal cycle in SSC is highly correlated with the diurnal cycle of the wavefield $\left(H_{\max }\right.$ and $\left.T_{s}\right)$ and in the magnitude of $u_{\text {max }, \mathrm{ADV}}$ (Figures $5 \mathrm{c}-5 \mathrm{~g}$ ). The maximum values of $u_{\text {max }, \mathrm{ADV}}$ during daytime $\left(0.15-0.35 \mathrm{~m} \mathrm{~s}^{-1}\right)$ were mainly caused by waves from passenger ships [Hofmann et al., 2008b]. Since resuspension increases with increasing $u_{\max , \mathrm{ADV}}$, the passenger ships contributed to the elevated SSC during daytime. In addition, the more intense ship traffic during daytime caused frequent events of ship waveinduced resuspension such that particle settling between two consecutive events was too slow to remove the particles completely from the water column that were introduced by the previous event (Figures $5 \mathrm{c}-5 \mathrm{~g}$ ). Hence, resuspension of particles during daytime exceeds the loss because of settling and horizontal transport, leading to an increasing concentration of suspended particles in the water column.

[31] During periods of moderate and strong onshore wind, which occur rather infrequently at the study site LG [Hofmann et al., 2008b], the wavefield $\left(H_{\max }\right.$ and $\left.T_{s}\right)$ and the resultant $u_{\text {max,ADV }}$ and SSC did not show a distinct diurnal cycle as described for ship wave-dominated days (Figure 5). Following the dynamics of the wind events, $u_{\max , \mathrm{ADV}}$ and SSC are high over much longer time periods (several hours) compared to the passage of a single ship-wave group (several minutes) (Figure 5). Especially during periods where $u_{\text {max,ADV }}$ were continuously high $\left(\sim 0.3 \mathrm{~m} \mathrm{~s}^{-1}\right)$ over at least one hour, SSC reached values up to $200-400 \mathrm{mg} \mathrm{L}^{-1}$ and exceeded SSC observed on days dominated by ship waves (Figure 5). During the same wind event, however, and at comparable values of $u_{\max , \mathrm{ADV}}(20: 30-21: 30 \mathrm{LT}$ and 22:30-23:30 LT on 16 August 2005), the observed SSC were considerably different $\left(200\right.$ and $350 \mathrm{mg} \mathrm{L}^{-1}$, respectively; Figures $51-5 n$ ). One possible explanation is that sediment resuspension is a gradual process that is correlated with time. During the first time period the sediment top layer was gradually eroded and spatially distributed through the whole water column and over the entire littoral zone. During 

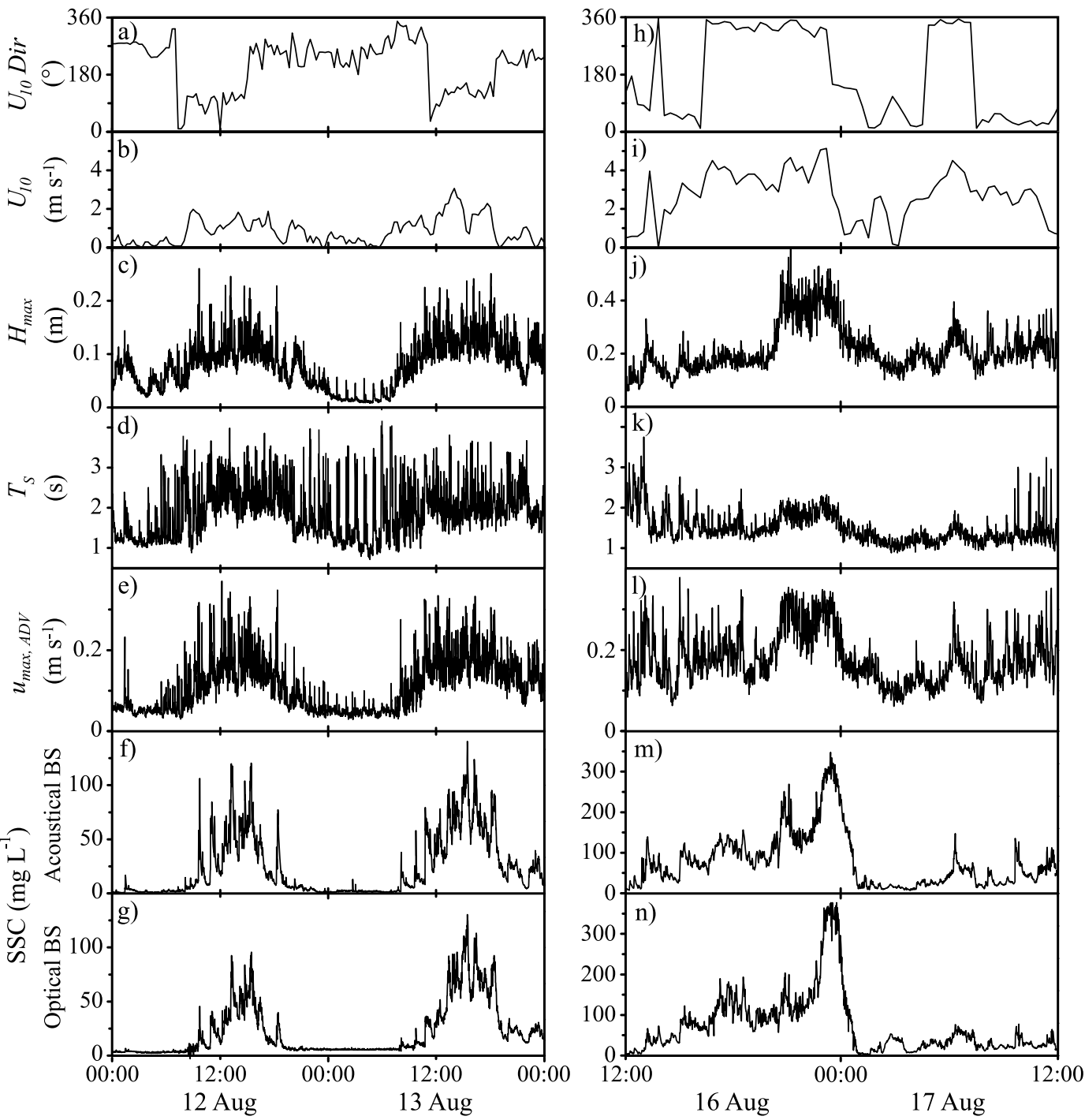

Figure 5. Times series of the (a) wind direction $\left(U_{10}\right.$ Dir), (b) wind speed $\left(U_{10}\right)$, (c) maximum wave height $\left(H_{\max }\right),(\mathrm{d})$ significant wave period $\left(T_{s}\right)$, (e) maximum near-bottom current velocity $\left(u_{\text {max,ADV}}\right)$, (f) suspended sediment concentration (SSC) calculated from the acoustical backscatter strength, and (g) SSC calculated from the optical backscatter strength for a ship wave (12 and 13 August 2005); (h-n) the same as Figures 5a-5g, except for a wind wave-dominated time period (16 and 17 August 2005).

the second time period, the previously and partially still resuspended particles were easily remobilized and added once more to the water column. At the same time, the gradual process of resuspension added newly remobilized particles to the water column, which increased the SSC further and established a new equilibrium. Another explanation for the observed pattern may be spatiotemporal changes in the SSC due to heterogeneous sediment distribution and properties in the vicinity of the study site combined with horizontal transport.

\subsection{Relationship Between the Maximum Near-Bottom Current Velocity and the Suspended Sediment Concentration}

[32] The relation between $u_{\max , \mathrm{ADV}}$ and the $\mathrm{SSC}_{\mathrm{ADV}}$ was exemplarily evaluated for August 2005 (Figure 6), when both wind and ship waves were present. The $\mathrm{SSC}_{\mathrm{ADV}}$ remains rather constant for small $u_{\text {max,ADV }}$ and increases rapidly with increasing $u_{\text {max,ADV }}$ above a certain level of $u_{\text {max,ADV }}$, which supports the concept that a threshold value of $u_{\max }, u_{\max , \text { res }}$, is required for resuspension. This threshold value was estimated by fitting the following model to the data:

$$
\log \mathrm{SSC}_{\mathrm{ADV}}=\left(\begin{array}{cc}
A, & u_{\max , \mathrm{ADV}} \leq C \\
A+B\left(\log u_{\max , \mathrm{ADV}}-\log C\right), & u_{\max , \mathrm{ADV}}>C
\end{array}\right)
$$

where the model parameter $A$ corresponds to the $\log$ $\left(\mathrm{SSC}_{\mathrm{ADV}}\right.$,base $)$ and $\mathrm{SSC}_{\mathrm{ADV} \text {,base }}$ is the mean background $\mathrm{SSC}_{\mathrm{ADV}} \cdot B$ is the slope of the curve above the point of intersection and $C$ corresponds to the threshold velocity, $u_{\text {max,res, }}$, above which wave-generated currents lead to resuspension. The parameter values were obtained by a least squares fit, providing $A=0.40, B=2.84$, and $C=0.09 \mathrm{~m} \mathrm{~s}^{-1}$. Hence, the mean background $\mathrm{SSC}_{\mathrm{ADV} \text {,base }}$ is about $2.5 \mathrm{mg} \mathrm{L}^{-1}$ (Figure 6; equation (3)), and the threshold flow velocity 

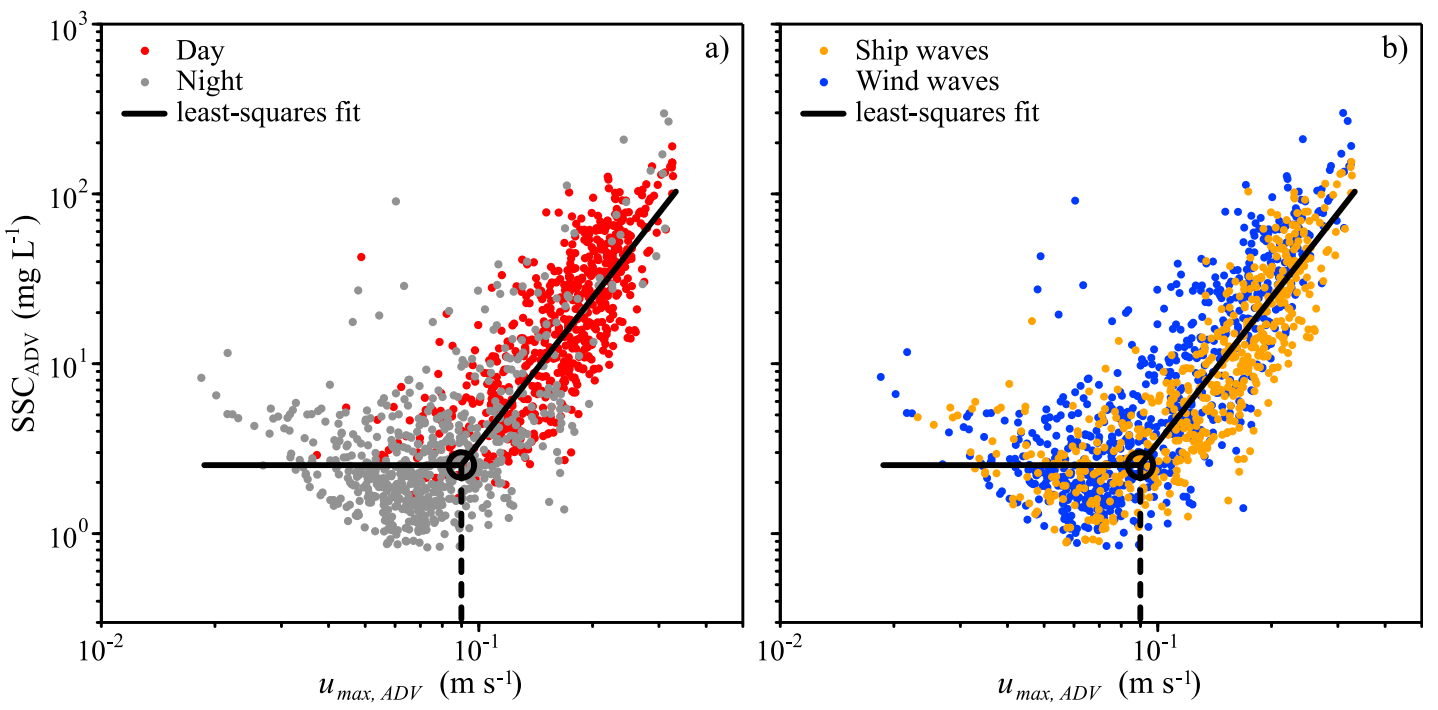

Figure 6. Scatterplot of the maximum near-bottom current velocity $\left(u_{\max , \mathrm{ADV}}\right)$ and the suspended sediment concentration ( $\mathrm{SSC}_{\mathrm{ADV}}$ ), calculated from the acoustic backscatter strength (ABS) of the $\mathrm{ADV}$, at about $1 \mathrm{~m}$ water depth during August 2005. (a) Distinction between measurements during daytime (red dots, 09:00-21:00 LT) and at night (gray dots, 21:00-09:00 LT). (b) Distinction between time intervals where wind waves (blue dots) or ship waves (orange dots) dominate. Each dot represents the data for a 30 min time interval. The black line represents the result from a least squares fit of the model (equation (3)). The point of intersection (open black circle) between the horizontal black line (mean background of the $\mathrm{SSC}_{\mathrm{ADV}}$,base) and the inclined black line (power law) marks the threshold of $u_{\max , \mathrm{ADV}}$ for resuspension $\left(0.09 \mathrm{~m} \mathrm{~s}^{-1}\right.$, dashed black line).

required for particle remobilization is $\sim 0.09 \mathrm{~m} \mathrm{~s}^{-1}$ (dashed black line). This threshold current velocity for resuspension, determined experimentally from $\mathrm{SSC}_{\mathrm{ADV}}$ and velocity measurements, lies within the range of the value calculated from the empirical relation $\left(u_{\text {max,res }} \sim 0.08 \mathrm{~m} \mathrm{~s}^{-1}\right.$; equation (2)) in combination with the estimate of particle density and median grain size of suspended sediments at the study site LG. In the following statistical analyses the higher value $u_{\text {max,res }}$ of $0.09 \mathrm{~m} \mathrm{~s}^{-1}$ was used as the threshold for resuspension.

[33] The separation of the time series into daytime (red dots) and nighttime (gray dots) revealed that wave-induced resuspension indicated by high $u_{\max , \mathrm{ADV}}$ and $\mathrm{SSC}_{\mathrm{ADV}}$ occurred mainly during daytime (Figure 6a). At night, $u_{\max , \mathrm{ADV}}$ and $\mathrm{SSC}_{\mathrm{ADV}}$ were mostly very low $\left(0.02-0.10 \mathrm{~m} \mathrm{~s}^{-1}\right.$ and $\left.1-10 \mathrm{mg} \mathrm{L}^{-1}\right)$, indicating a minor importance for resuspension. Further, resuspension induced by ship waves (Figure 6b, orange dots) was in the same order of magnitude and is characterized by the same statistical relation as resuspension induced by wind waves (Figure 6b, blue dots).

\subsection{Relative Importance of Wind and Ship Waves for Resuspension}

[34] The characterization of the surface wavefield allows us to distinguish ship and wind waves by their corresponding properties [Hofmann et al., 2008b]. The importance of wind and ship waves for resuspension can be quantified by the number of 1.1 min time periods during which wind and ship waves exceed $u_{\text {max,res }}$, respectively. The number of these time intervals relative to the total number of time periods measured within the respective month (relative monthly frequency of resuspension, $\mathrm{RF}_{\text {res }}$ ) is depicted in Figure 7. Daytime and nighttime are considered separately to emphasize that not only seasonal but also diurnal patterns occur (Figures $7 \mathrm{a}$ and $7 \mathrm{~b}$ ).
[35] During daytime, the overall proportion of waves that exceed the threshold flow velocity for resuspension of $0.09 \mathrm{~m} \mathrm{~s}^{-1}$ was significantly higher in summer (MarchOctober) than in winter (November-February), ranging from $16 \%$ to $74 \%$ and $8 \%$ to $15 \%$, respectively (Figure $7 \mathrm{a}$ ). This difference between summer and winter can be attributed to the strongly reduced ship traffic during winter. The proportion of wind waves that contribute to resuspension remained relatively constant throughout the whole year and accounted for $4 \%-35 \%$, whereas the proportion of ship waves increased significantly in summer, ranging from 5\% in March to $50 \%$ in June. In winter, the proportion of ship waves that cause resuspension was strongly reduced to $2 \%-6 \%$.

[36] Apart from the seasonal pattern, ship waves caused a pronounced diurnal pattern in resuspension. At night, the overall proportion of waves that exceed the threshold for resuspension $(4 \%-33 \%)$ was much lower than during the day (Figure $7 b$ ) and did not indicate a seasonal pattern. Also, the observed diurnal pattern can be attributed to reduced ship traffic at night. The variability in the relative frequency of resuspension $\left(\mathrm{RF}_{\text {res }}\right)$ of wind waves, in contrast, can be explained by their irregular occurrence. Strong onshore wind events were responsible for the high values in August, March, and July, and the absence of onshore wind events explains the low values in November and April (Figure 7). Hence, the potential for resuspension is especially low during winter and at night, where $86-93 \%$ and $74-96 \%$ of the time the wavegenerated near-bottom current velocities do not exceed the threshold velocity for resuspension.

[37] On an annual mean, the proportion of the time at the study site during which wave-induced resuspension can occur is about $25 \%$. Of that, $46 \%$ is caused by wind waves and $54 \%$ by ship waves, suggesting that the relative impor- 


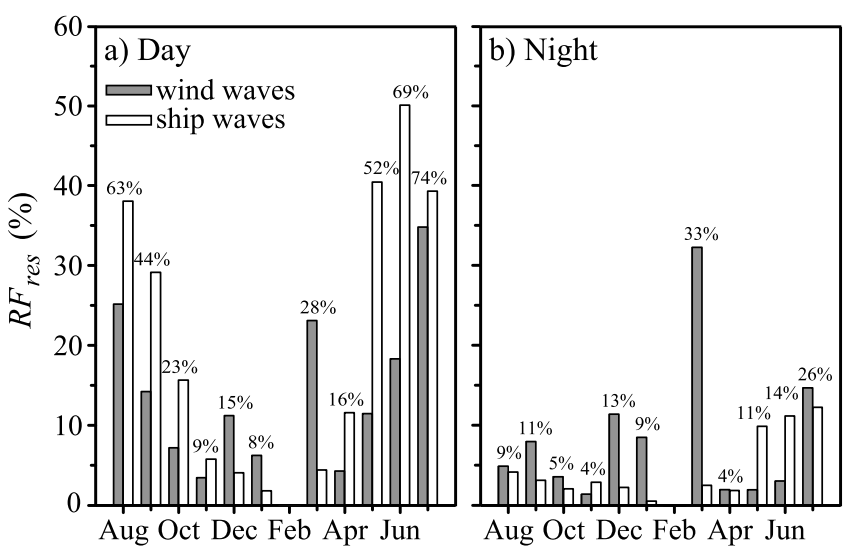

Figure 7. Relative importance of wind and ship waves for resuspension expressed in terms of the relative monthly frequency of resuspension $\left(\mathrm{RF}_{\text {res }}\right)$, the proportion of time where the maximum near-bottom current velocity exceeds the calculated threshold for resuspension $\left(u_{\text {max,res }}=0.09 \mathrm{~m} \mathrm{~s}^{-1}\right)$, at $1 \mathrm{~m}$ water depth. The statistics distinguish between wind (gray bars) and ship (white bars) waves and are based on measurements between August 2005 and July 2006. (a) During the day (09:00-21:00 LT). (b) At night (21:00-09:00 LT). The percentage at the top of each pair of bars is the sum of $\mathrm{RF}_{\text {res }}$ due to wind and ship waves. The maximum nearbottom current velocity $u_{\text {max,Ps }}$ was calculated from wave parameters, which were derived from the pressure sensor time series. Values of $u_{\text {max,Ps }}$ below the calculated threshold for resuspension were excluded from the data sets and are expressed as the difference between the percentage at the top of each pair of bars and 100\% (apart from February, for which no data are available).

tance of ship versus wind waves for the occurrence of resuspension can be characterized by an importance ratio of $54 \% / 46 \%$. The robustness of this ratio against reasonably higher $\left(0.11 \mathrm{~m} \mathrm{~s}^{-1}\right)$ and lower $\left(0.07 \mathrm{~m} \mathrm{~s}^{-1}\right) u_{\text {max,res }}$ values, which may be associated with different sediment properties, was tested by a sensitivity analysis. This analysis revealed that the relative importance of wind and ship waves for the occurrence of sediment resuspension is almost independent of the actual value of $u_{\text {max,res. }}$. Considering all time periods during which resuspension can occur (i.e., during which $\left.u_{\text {max }, \mathrm{PS}} \geq u_{\text {max,res }}\right)$ we calculated the annual mean $\mathrm{SSC}_{\mathrm{ADV}}$ and the annual cumulative $\mathrm{SSC}_{\mathrm{ADV}}$ for ship and wind waves. The ratio of the annual mean $\mathrm{SSC}_{\mathrm{ADV}}$ for ship versus wind wave-induced resuspension events turned out to be $46 \% / 54 \%$, suggesting that on average $\mathrm{SSC}_{\mathrm{ADV}}$ is slightly larger during wind wave-induced resuspension events. However, because the potential for resuspension events occurs more often in association with ship waves than with wind waves, the ratio of the annual cumulative $\mathrm{SSC}_{\mathrm{ADV}}$ for ship versus wind waves becomes 1.0. Hence, the cumulative $\mathrm{SSC}_{\mathrm{ADV}}$ associated with wave-induced resuspension is equal for ship and wind waves and thus is not in conflict with the conclusion that ship waves are as important for resuspension as wind waves. Unfortunately, the cumulative SSC cannot be interpreted as the total amount of resuspended material because SSC is a property characterizing the state of the sampled water volume resulting from the balance of different fluxes: the flux of particles mobilized from the sediment (i.e., resuspension of particles) and subsequently transported to the sample volume and the import and export fluxes of particles due to sedimentation and horizontal transport. Hence, the amount of particles mobilized by resuspension cannot be quantified from SSC without knowing the fluxes due to horizontal and vertical transport. Nevertheless, the ratio of the cumulative $\mathrm{SSC}_{\mathrm{ADV}}$ suggests that resuspension events by wind and ship waves have a similar effect on SSC even in the long-term average.

[38] The sedimentation rates measured by the five sediment traps at the study site indicated a change in sediment resuspension with depth and in relation to the wavefield (dominated by wind or ship waves). The comparison of two successive 5 day periods revealed that the sedimentation rate at all depths during a strong onshore wind event (1520 September 2005; Figure 8a) was significantly larger than during a ship wave-dominated time period (20-25 September 2005; Figure 8b). During both periods the sedimentation rate decreased with increasing water depths, as did the near-bottom current velocities. Note that the large sedimentation rate (gross sedimentation) at shallower depths does not imply a large sediment accumulation rate, but is rather a consequence of the permanent interplay between resuspension and later deposition in the sediment traps. During the period of the strong onshore wind event, high sedimentation of particles was not only at $0.6 \mathrm{~m}$, as for the ship wave-dominated period, but also at greater water depths (Figure 8). This may be caused by increased resuspension at the deployment depths of the sediment traps due to the large-amplitude wind waves generated by the strong onshore wind and by an increased near-bottom, cross-shore-directed transport of particles resuspended at shallower depths. In the sediment traps the organic fraction $(5 \%-22 \%)$ was small compared to the inorganic fraction (78-95\%) (Figure 8). However, we did measure a difference in the spatial distribution of the organic fraction. During the wind wave-dominated time period, the organic fraction was equally distributed with depth. In contrast, during the ship wave-dominated period, the organic fraction was significantly increased at water depths above $0.9 \mathrm{~m}$ compared to the very shallow littoral.

\section{Discussion}

\subsection{Patterns and Relative Importance of Wind and Ship Wave-Induced Resuspension}

[39] The shallow nearshore zones of lakes are highly exposed to surface waves that generate large near-bottom current velocities and shear. The surface wavefield at the study site LG, Lake Constance, is dominated by wind waves in winter and ship waves in summer [Hofmann et al., 2008b]. The wavefield characteristics observed in Lake Constance can be expected to be comparable to the wavefield in many prealpine and alpine lakes in Germany and Switzerland, but also in other enclosed and semienclosed water bodies with limited fetch lengths that experience ship traffic. One important effect of surface waves is resuspension of bottom sediment. Since wind and ship wave have significantly different properties and occurrence patterns they cause considerably different temporal patterns of resuspension.

[40] Wind wave-induced sediment resuspension is infrequent and highly dependent on the wind direction, speed, and fetch length. At the study site LG only strong onshore winds cause comparable or higher SSC as the regularly occurring ship waves at the same water depth. During wind 


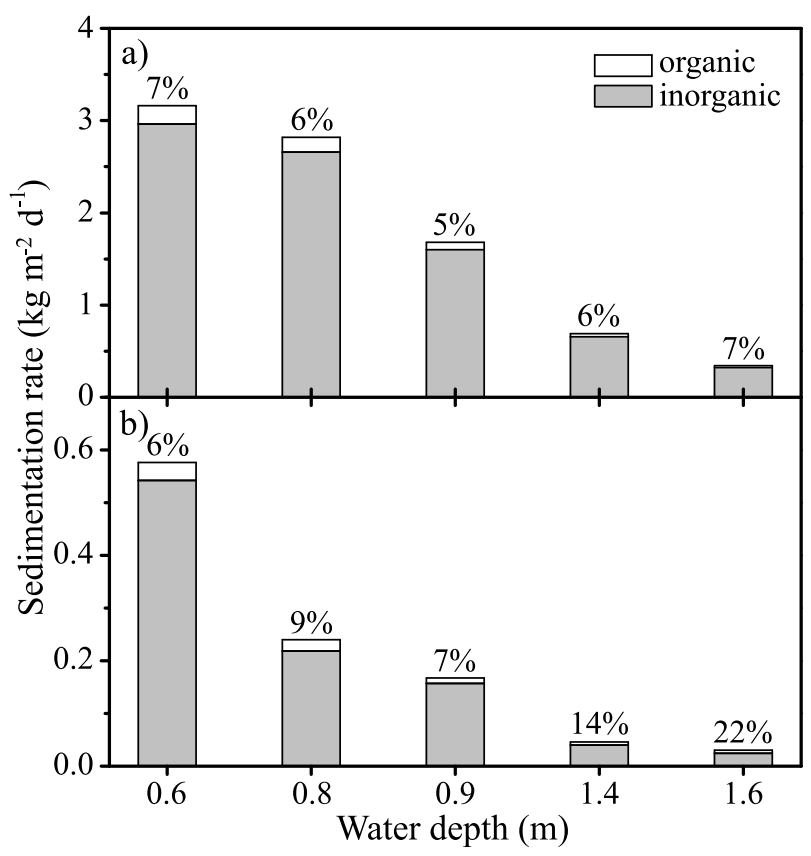

Figure 8. Sedimentation rate of organic (white bars) and inorganic (gray bars) particles measured by sediment traps. (a) During a time period with strong onshore wind (1520 September 2005). (b) During a time period with no or calm wind (wavefield was dominated by ship waves, 20-25 September 2005). The percentage at the top of each bar represents the ratio between the organic and inorganic fractions. Note that the organic fraction is larger by a factor of about 2.5 if expressed in terms of volume rather than mass.

events, the wave heights $\left(H_{\max }\right)$ and the resultant wind wave-generated maximum near-bottom current velocities and the SSC remain almost constant over some hours (Figures $4 \mathrm{~b}$ and $5 \mathrm{~h}-5 \mathrm{n}$ ). This can be explained by an equilibrium formed between the resuspension, settling, and transport of particles. During these specific time periods the concentration of suspended particles and thus the sedimentation rate is enhanced compared to an equal period of time when ship waves dominate (Figure 8).

[41] The passage of a single ship increases the near-bottom current velocities drastically and causes a high and distinct peak in the SSC because of the resuspension of a wide range of grain sizes (Figure 2a), where the coarser particles resettle quickly and finer particles remain in the water column for several minutes (Figures 2a and 4a) [Erm and Soomere, 2006].

[42] The statistical relationship between near-bottom current velocities and $\mathrm{SSC}_{\mathrm{ADV}}$ depicted in Figure 6 reflects a consistent pattern, as observed for the long-term measurements at the study site LG. Especially during daytime in summer, where ship waves dominate the wavefield, the near-bottom current velocities remain above the threshold value for resuspension of $0.09 \mathrm{~m} \mathrm{~s}^{-1}$ (Figures 5e and 6). The regular ship traffic further reduces settling of suspended particles between subsequent wave groups. Thus, ship wave-induced resuspension causes a diurnal cycle in the measured SSC with high values by day and low values at night (Figures 5f, 5g, and 7). Such periodicity caused by navigation was also observed by Garrad and Hey [1987] in a river system and by Erm et al. [2009] on the shelf of a semienclosed sea. The "tourist cruise ship season" of passenger ships during summer and their near absence during winter [Hofmann et al., 2008b] cause further a seasonal pattern in the occurrence of sediment resuspension (Figure 7).

[43] At the study site, the threshold for resuspension $u_{\text {max,res }}$ is exceeded during $25 \%$ of the time (Figure 7 ). Ship waves contribute $54 \%$ and wind waves $46 \%$ of the time periods with resuspension. The frequent resuspension of particles caused by ship waves, especially during summer, results in an overall higher number of resuspension events due to ship traffic than due to wind forcing, owing to the sporadic nature of wind events and the shorter wavelengths of wind waves. Ship waves as an anthropogenic force in the littoral zone apparently have the same significance for sediment resuspension as wind waves.

[44] The important role of ship waves in resuspension is not only a consequence of their comparatively frequent occurrence but also of the fact that they have longer wave periods and thus larger wavelengths than wind waves. For a given wave height and water depth, the maximum wavegenerated near-bottom current velocity is determined by the wave period or length (equation (1)) [Kundu and Cohen, 2002]. At the site LG, ship waves have wave periods of $\sim 3-6 \mathrm{~s}$ and associated deepwater wavelengths of $\sim 13-50 \mathrm{~m}$, depending on the ship type (ferry, $\sim 4 \mathrm{~s}$ and $\sim 20 \mathrm{~m}$; passenger ships, $\sim 3 \mathrm{~s}$ and $\sim 13 \mathrm{~m}$; catamaran, $\sim 6 \mathrm{~s}$ and $\sim 50 \mathrm{~m}$ ). Wind waves, in contrast, have wave periods of $\sim 2 \mathrm{~s}$ and wavelengths of only $\sim 2-8 \mathrm{~m}$ [Hofmann et al., 2008b]. The consequences of the different wave periods of wind and ship waves are illustrated in Figure 9. At the same water depth, ship waves induce much higher near-bottom current velocities than wind waves of the same wave height (Figure 9a) and therefore affect the ecosystem at much greater depths than the wind waves (Figure 9c). Furthermore, the higher near-bottom current velocities of ship waves (at the same water depth and wave height) remobilize larger particles than wind waves (Figures 9a and 9b). Wind waves, on the other hand, need much shallower water or higher wave heights compared to ship waves to remobilize particles of the same size (Figure 9).

[45] Regularly occurring resuspension events are known to prevent sediment consolidation and the development of a cohesive sediment layer [e.g., Dyer, 1986; Schoellhamer, 1996]. These newly deposited and unconsolidated sediments are more susceptible to resuspension by even relatively weak winds or local currents [e.g., Lindholm et al., 2001; Schoellhamer, 1996] and lead to strong impulse loads of suspended particles. Since we have demonstrated that ship waves lead to regular resuspension events, which prevent the formation of cohesive sediments, ship traffic may significantly contribute to erosion of sediments in the littoral zone [e.g., Bauer et al., 2002; Soomere et al., 2009].

[46] The sedimentation rate as well as the grain size of settling particles decreases rapidly with increasing water depth (Figures 2b and 8). Nevertheless, it remains unclear whether resuspension takes place mainly in the shallow littoral followed by transport of particles in offshore direction, in which the large particles resettle first, or whether this distribution is caused by a weaker impact of ship waves and finer sediment in the deeper littoral. However, since ship waves are an important factor for the sediment resuspension at the study site LG, especially during daytime in summer, 
they may contribute to the spatial distribution of sediments. In particular, we measured within the suspended matter an increase of the organic and a decrease of the inorganic particle fraction with increasing water depth (Figure 8b). This observation indicates that, in contrast to inorganic particles, only a reduced proportion of the organic particles mobilized by ship waves at shallow depths settle again

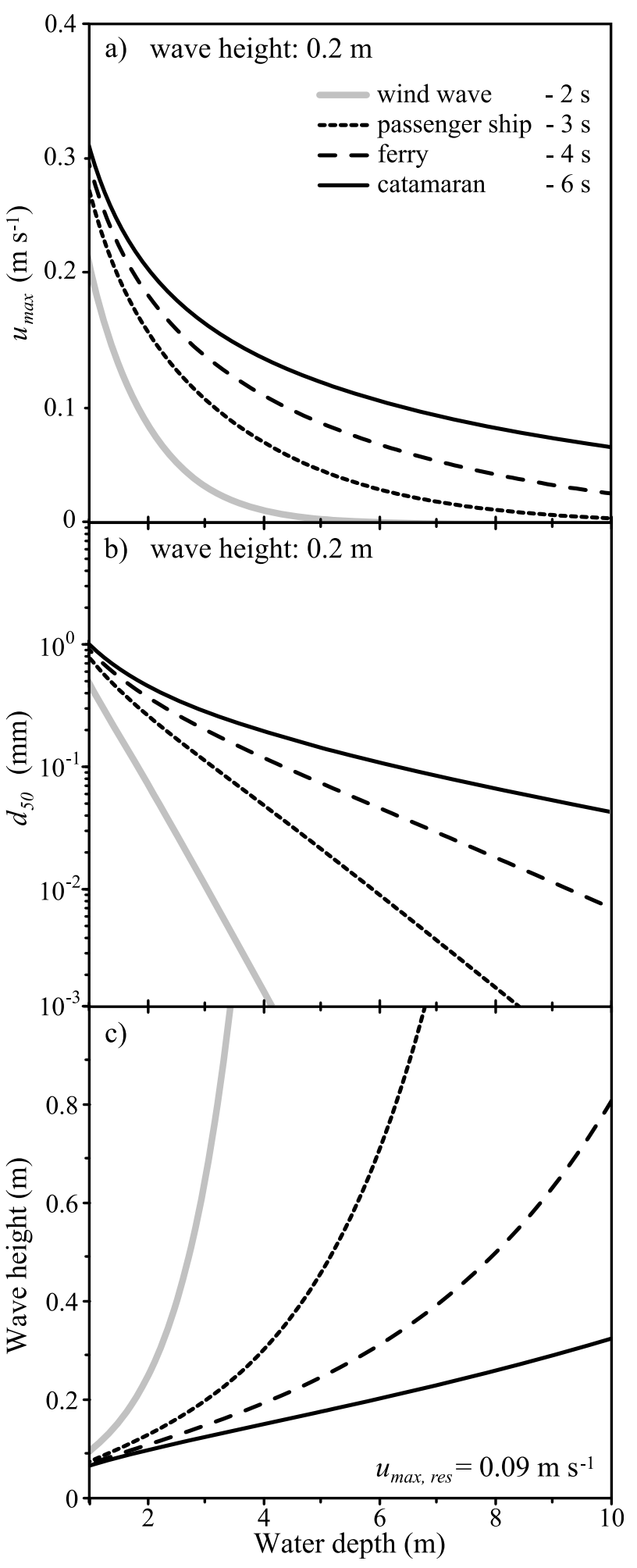

within the shallow littoral zone, but may rather be exported to the deep littoral.

\subsection{Ecological Consequences of Ship Waves in the Littoral Zone}

[47] Resuspension of particles has several ecological consequences, which are intensified by ship-induced resuspension. Ship waves cause strong impulse loads of suspended particles in the water column. These pulses of suspended particles alter the light climate in the littoral zone by reducing water transparency and light penetration [e.g., Erm and Soomere, 2006; Hofmann et al., 2008a; Van Duin et al., 2001]. Ship wave-induced resuspension occurs especially during daytime and in summer and thus affects the availability of light for the growth of phytoplankton [Schallenberg and Burns, 2004] and biofilms in particular [Francoeur and Biggs, 2006], and affect hunting success of visually orientated fishes [Utne-Palm, 2004]. Furthermore, the frequent occurrence of ship wave-induced resuspension limits or even suppresses settling and growth of macrophytes [Eriksson et al., 2004]. The permanent shifting of fine-grained particles alters the habitat structure on small scales in terms of spatially reduced (mainly deep littoral) or increased (mainly shallow littoral) availability of cavities (interstitial) for benthic invertebrates and nematodes [e.g., Peters and Traunspurger, 2005; Scheifhacken et al., 2007].

\section{Conclusions}

[48] Sediment resuspension in lakes induced by surface waves is pronounced in the shallow littoral zone, where surface waves are the dominant hydrodynamic force. The process of sediment resuspension and the resulting increase in SSC in the littoral zone is highly related to the properties of the surface wavefield. The different wave types, wind and ship waves, cause different temporal patterns in resuspension and particle distribution. Sediment resuspension induced by wind waves occurs sporadically and less frequently than ship wave-induced resuspension. The periodic and regular occurring ship waves, especially those of passenger ships, during daytime in summer cause a substantial increase in SSC in the shallow littoral. Ship waves thus create a diurnal cycle as well as a seasonal pattern in the SSC and resuspension. On an annual scale, ship and wind wave-induced resuspension can be of equal significance. The importance of ship waves is further enhanced since they typically have longer wavelengths at most lake shores than wind waves and thus affect deeper water zones and a much broader section of the littoral zone. The frequent occurrence of ship waves leads to frequent resuspension events, which counteract the consolidation of

Figure 9. Potential forcing of different wave types in terms of wave period: wind ( $\sim \mathrm{s})$, passenger ships $(\sim 3 \mathrm{~s})$, the ferry $(\sim 4 s)$, and catamarans $(\sim 6 \mathrm{~s})$ that are typical for Lake Constance as a function of depth (littoral zone). (a) Maximum wave-generated near-bottom current velocity $\left(u_{\max }\right)$ at a constant wave height of $0.2 \mathrm{~m}$ (equation (1)). (b) Remobilizable median grain size $\left(d_{50}\right)$ at a constant wave height of $0.2 \mathrm{~m}$ (equation (2)). (c) Required wave height for the remobilization of particles $\left(u_{\text {max,res }}=0.09 \mathrm{~m} \mathrm{~s}^{-1}\right)$ at the study site LG (equation (1)). Note that all calculations are based on linear wave theory. 
bottom sediments. Wave forcing by ships thus may make sediments more susceptible to resuspension. Additionally, ship wave-induced resuspension may have a particularly large impact on the biota in the littoral zone by decreasing the availability of light for photosynthesis because of increased loads of suspended particles especially during daytime.

[49] Acknowledgments. We thank Georg Heine and his colleagues from the electronic and mechanical workshop at the University of Konstanz for technical assistance and for the development of the pressure sensors. We gratefully acknowledge the help of the technical staff at the Limnological Institute and many students during fieldwork and data analysis. We further thank Martin Wessels and Karin Popp from the ISF Langenargen for providing the grain size analyzer and their help in the laboratory. The helpful and valuable comments of the anonymous referees improved the manuscript. This work was supported by the German Research Foundation (DFG) within the framework of the Collaborative Research Center 454 "Littoral Zone of Lake Constance."

\section{References}

Allan, J. C., and R. M. Kirk (2000), Wind wave characteristics at Lake Dunstan, South Island, New Zealand, N. Z. J. Mar. Freshwater Res., 34, 573-591, doi:10.1080/00288330.2000.9516959.

Ball, D. F. (1964), Loss-on-ignition as an estimate of organic matter and organic carbon in non-calcareous soils, J. Soil Sci., 15, 84-92, doi:10.1111/j.1365-2389.1964.tb00247.x.

Bauer, B. O., et al. (2002), Estimating boat-wake-induced levee erosion using sediment suspension measurements, J. Waterw. Port Coastal Ocean Eng., 128(4), 152-162.

Bhowmik, N. G. (1975), Boat-generated waves in lakes, J. Hydraul. Div. Am. Soc. Civ. Eng., 101(11), 1465-1468.

Bhowmik, N. G., T. W. Soong, W. F. Reichelt, and N. M. L. Seddik (1991), Waves generated by recreational traffic on the upper Mississippi River system, Res. Rep. 117, pp. 33-35, Ill. State Water Surv., Champaign.

Braun, E., and K. Schärpf(1990), Internationale Bodensee-Tiefenvermessung, 98 pp., Int. Gewässerschutzkomm. für den Bodensee, Stuttgart, Germany.

Brown, E., et al. (2005), Waves, Tides and Shallow-Water Processes, 2nd ed., 227 pp., Butterworth-Heinemann, Boston, Mass.

Defendi, V., et al. (2010), Estimating sediment transport from acoustic measurements in the Venice Lagoon inlets, Cont. Shelf Res., 30(8), 883-893, doi:10.1016/j.csr.2009.12.004.

Dyer, K. R. (1986), Coastal and Estuarine Sediment Dynamics, 342 pp., John Wiley, Chichester, U. K.

El Ganaoui, O., et al. (2004), The deposition and erosion of cohesive sediments determined by a multi-class model, Estuarine Coastal Shelf Sci., 60(3), 457-475, doi:10.1016/j.ecss.2004.02.006.

Eriksson, B. K., et al. (2004), Effects of boating activities on aquatic vegetation in the Stockholm archipelago, Baltic Sea, Estuarine Coastal Shelf Sci., 61(2), 339-349, doi:10.1016/j.ecss.2004.05.009.

Erm, A., and T. Soomere (2006), The impact of fast ferry traffic on underwater optics and sediment resuspension, Oceanologia, 48, suppl., 283-301.

Erm, A., et al. (2009), Monitoring wave-induced sediment resuspension, Estonian J. Eng., 15(3), 196-211.

Fenton, J. D., and W. D. McKee (1990), On calculating the lengths of water waves, Coastal Eng., 14(6), 499-513, doi:10.1016/0378-3839(90) 90032-R

Francoeur, S., and B. Biggs (2006), Short-term effects of elevated velocity and sediment abrasion on benthic algal communities, Hydrobiologia, 561(1), 59-69, doi:10.1007/s10750-005-1604-4.

Fugate, D. C., and C. T. Friedrichs (2002), Determining concentration and fall velocity of estuarine particle concentrations using ADV, OBS and LISST, Cont. Shelf Res., 22, 1867-1886, doi:10.1016/S0278-4343(02) 00043-2.

Garrad, P. N., and R. D. Hey (1987), Boat traffic, sediment resuspension and turbidity in a Broadland River, J. Hydrol., 95(3-4), 289-297, doi:10.1016/0022-1694(87)90007-2.

Guy, H. P. (1969), Laboratory theory and methods for sediment analysis, U.S. Geol. Surv. Tech. Water Resour. Invest., Book 1, Chap. C1, 58 pp.

Håkanson, L. (2005), A new dynamic model for suspended particulate matter (SPM) in lakes, Int. Rev. Hydrobiol., 90(5-6), 603-636, doi:10.1002/ iroh.200510790.
Hallermeier, R. J. (1980), Sand motion initiation by water waves: Two asymptotes, J. Waterw. Port Coastal Ocean Div. Am. Soc. Civ. Eng., 106, 299-318.

Hamblin, P. F. (1989), Observations and model of sediment transport near the turbidity maximum of the upper Saint Lawrence Estuary, J. Geophys. Res., 94(C10), 14,419-14,428, doi:10.1029/JC094iC10p14419.

Hawley, N., and B. M. Lesht (1992), Sediment resuspension in Lake St. Clair, Limnol. Oceanogr., 37(8), 1720-1737, doi:10.4319/1o.1992.37.8.1720.

Hofmann, H., et al. (2008a), Wave-induced variability of the underwater light climate in the littoral zone, Verh. Int. Ver. Limnol., 30(4), 627-632.

Hofmann, H., et al. (2008b), The relative importance of wind and ship waves in the littoral zone of a large lake, Limnol. Oceanogr., 53(1), 368-380, doi:10.4319/lo.2008.53.1.0368.

Hofmann, H., et al. (2008c), Temporal and spatial scales of water level fluctuations in lakes and their ecological implications, Hydrobiologia, 613(1), 85-96, doi:10.1007/s10750-008-9474-1.

Hofmann, H., et al. (2010), Wave-induced release of methane: Littoral zones as a source of methane in lakes, Limnol. Oceanogr., 55(5), 1990-2000, doi:10.4319/1o.2010.55.5.1990.

Houser, C. (2010), Relative importance of vessel-generated and wind waves to salt marsh erosion in a restricted fetch environment, J. Coastal Res., 26(2), 230-240, doi:10.2112/08-1084.1.

IAHR Working Group on Wave Generation and Analysis (1989), List of seastate parameters, J. Waterw. Port Coastal Ocean Eng., 115, 793-808.

Kelpsaite, L., et al. (2009), Energy pollution: The relative influence of wind-wave and vessel-wake energy in Tallinn Bay, the Baltic Sea, J. Coastal Res., Spec. Issue, 56, 812-816.

Komen, G. J., et al. (1996), Dynamics and Modelling of Ocean Waves, 532 pp., Cambridge Univ. Press, Cambridge, U. K.

Kristensen, P., et al. (1992), Resuspension in a shallow eutrophic lake, Hydrobiologia, 228, 101-109, doi:10.1007/BF00006481.

Kundu, P. K., and I. M. Cohen (2002), Fluid Mechanics, 730 pp., Academic, London.

Le Blond, P. H., and L. A. Mysak (1978), Waves in the Ocean, 602 pp., Elsevier, Amsterdam.

Lindholm, T., et al. (2001), Effects of ship traffic on archipelago waters off the Långnäs harbour in Åland, SW Finland, Hydrobiologia, 444(1-3), 217-225, doi:10.1023/A:1017518131889.

Luettich, R. A., Jr., et al. (1990), Dynamic behavior of suspended sediment concentrations in a shallow lake perturbed by episodic wind events, Limnol. Oceanogr., 35(5), 1050-1067, doi:10.4319/lo.1990.35.5.1050.

Lynch, J. F., et al. (1994), Determining suspended sediment particle size information from acoustical and optical backscatter measurements, Cont. Shelf Res., 14(10-11), 1139-1165, doi:10.1016/0278-4343(94)90032-9.

Maynord, S. T. (2005), Wave height from planing and semi-planing small boats, River Res. Appl., 21(1), 1-17, doi:10.1002/rra.803.

Nielson, P. (1994), Coastal Bottom Boundary Layers and Sediment Transport, 2nd ed., 324 pp., World Sci., Singapore.

Parchure, T. M., et al. (2001), Desktop method for estimating vesselinduced sediment suspension, J. Hydraul. Eng., 127(7), 577-587, doi:10.1061/(ASCE)0733-9429(2001)127:7(577).

Parnell, K. E., and H. Kofoed-Hansen (2001), Wakes from large highspeed ferries in confined coastal waters: Management approaches with examples from New Zealand and Denmark, Coastal Manage., 29(3), 217-237, doi:10.1080/08920750152102044.

Peters, L., and W. Traunspurger (2005), Species distribution of free-living nematodes and other meiofauna in littoral periphyton communities of lakes, Nematology, 7(2), 267-280, doi:10.1163/1568541054879520.

Pierson, D. C., et al. (2003), Long and short term variations in suspended particulate material: The influence on light available to the phytoplankton community, Hydrobiologia, 494, 299-304, doi:10.1023/ A:1025455424972.

Precht, E., et al. (2004), Oxygen dynamics in permeable sediments with wave-driven pore water exchange, Limnol. Oceanogr., 49(3), 693-705, doi:10.4319/lo.2004.49.3.0693.

Schallenberg, M., and C. W. Burns (2004), Effects of sediment resuspension on phytoplankton production: Teasing apart the influences of light, nutrients and algal entrainment, Freshwater Biol., 49(2), 143-159, doi:10.1046/j.1365-2426.2003.01172.x.

Scheifhacken, N., et al. (2007), Complex spatial and temporal patterns of littoral benthic communities interacting with water level fluctuations and wind exposure in the littoral zone of a large lake, Fundam. Appl. Limnol., 169(2), 115-129, doi:10.1127/1863-9135/2007/0169-0115.

Schoellhamer, D. H. (1996), Anthropogenic sediment resuspension mechanisms in a shallow microtidal estuary, Estuarine Coastal Shelf Sci., 43(5), 533-548, doi:10.1006/ecss.1996.0086. 
Søndergaard, M., et al. (1992), Phosphorus release from resuspended sediment in the shallow and wind-exposed Lake Arresø, Denmark, Hydrobiologia, 228, 91-99, doi:10.1007/BF00006480.

Soomere, T. (2005), Fast ferry traffic as a qualitatively new forcing factor of environmental processes in non-tidal sea areas: A case study in Tallinn Bay, Baltic Sea, Environ. Fluid Mech., 5(4), 293-323, doi:10.1007/ s10652-005-5226-1.

Soomere, T., and J. Engelbrecht (2005), Extreme elevations and slopes of interacting solitons in shallow water, Wave Motion, 41(2), 179-192, doi:10.1016/j.wavemoti.2004.06.006.

Soomere, T., et al. (2009), Implications of fast-ferry wakes for semisheltered beaches: A case study at Aegna Island, Baltic Sea, J. Coastal Res., Spec. Issue, 56, 128-132.

Sorensen, R. M. (1973), Ship-generated waves, Adv. Hydrosci., 9, 49-83.

Stumbo, R. M. (1999), The prediction, measurement, and analysis of wake wash from marine vessels, Mar. Technol., 36(4), 248-260.

Thevenot, M. M., and N. C. Kraus (1993), Comparison of acoustical and optical measurements of suspended material in the Chesapeake Estuary, J. Mar. Environ. Eng., 1, 65-79.
U.S. Army Coastal Engineering Research Center (2002), Shore Protection Manual, vol. 1, 532 pp., Books for Business, Washington, D. C.

Utne-Palm, A. C. (2004), Effects of larvae ontogeny, turbidity, and turbulence on prey attack rate and swimming activity of Atlantic herring larvae, J. Exp. Mar. Biol. Ecol., 310, 147-161, doi:10.1016/j.jembe.2004.04.005.

Van Duin, E. H. S., et al. (2001), Modeling underwater light climate in relation to sedimentation, resuspension, water quality and autotrophic growth, Hydrobiologia , 444, 25-42, doi:10.1023/A:1017512614680.

Vittori, G. (2003), Sediment suspension due to waves, J. Geophys. Res., 108(C6), 3173, doi:10.1029/2002JC001378.

Voulgaris, G., and S. T. Meyers (2004), Temporal variability of hydrodynamics, sediment concentration and sediment settling velocity in a tidal creek, Cont. Shelf Res., 24, 1659-1683, doi:10.1016/j.csr.2004.05.006.

H. Hofmann and F. Peeters, Environmental Physics, Limnological Institute, University of Konstanz, Mainaustr. 252, D-78465 Konstanz, Germany. (hilmar.hofmann@uni-konstanz.de)

A. Lorke, Institute for Environmental Sciences, University of KoblenzLandau, Fortstr. 7, D-76829 Landau, Germany. 